This is the peer reviewed version of the following article: Serra-Maluquer, X, Granda, E, Camarero, JJ, et al. Impacts of recurrent dry and wet years alter long-term tree growth trajectories. Journal of Ecology 2021; 109: 1561-1574, which has been published in final form athttps://doi.org/10.1111/1365-2745.13579. This article may be used for non-commercial purposes in accordance with Wiley Terms and Conditions for self-archiving.

\title{
1 Impacts of recurrent dry and wet years alter long-term tree growth
}

\section{trajectories}

4 Xavier Serra-Maluquer ${ }^{\mathrm{a}}$, Elena Granda ${ }^{\mathrm{a}, \mathrm{b}}$, J. Julio Camarero ${ }^{\mathrm{a}}$, Albert Vilà-Cabrera ${ }^{\mathrm{c}, \mathrm{d}}$, Alistair S.

5 Jump $^{\mathrm{d}}$, Raúl Sánchez-Salguero ${ }^{\mathrm{e}}$, Gabriel Sangüesa-Barreda ${ }^{\mathrm{f}}$, J. Bosco Imbert ${ }^{\mathrm{g}}$, Antonio Gazol ${ }^{\mathrm{a}}$.

6

$7 \quad{ }^{a}$ Instituto Pirenaico de Ecología. Avda. Montañana, 1005, Zaragoza 5009, Spain.

8 b Departamento de Ciencias de la Vida, Facultad de Ciencias, Universidad de Alcalá, 28805

9 Alcalá de Henares, Madrid, Spain.

$10{ }^{\mathrm{c}}$ CREAF, Bellaterra (Cerdanyola del Vallès), Catalonia, Spain.

11 d Biological and Environmental Sciences, Faculty of Natural Sciences, University of Stirling, 12 Stirling, FK9 4LA, Scotland, UK.

$13{ }^{\mathrm{e}}$ Departamento de Sistemas Físicos, Químicos y Naturales, Universidad Pablo de Olavide, Crta. 14 Utrera km 1, 41013, Sevilla, Spain.

$15{ }^{\mathrm{f}}$ Departamento de Ciencias Agroforestales, EiFAB-iuFOR, Universidad de Valladolid, Campus 16 Duques de Soria, 42004 Soria, Spain.

$17{ }^{\mathrm{g}}$ Departamento de Ciencias, Institute for Multidisciplinary Research in Applied Biology IMAB, 18 Universidad Pública de Navarra, Pamplona, Navarra, Spain.

20 Correspondence (Xavier Serra-Maluquer): 
1. Climate extremes, such as abnormally dry and wet conditions, generate abrupt shifts in tree growth, a situation which is expected to increase under predicted climate conditions. Thus, it is crucial to understand factors determining short- and long-term tree performance in response to higher frequency and intensity of climate extremes.

2. We evaluated how three successive droughts and wet years influenced short- and long term growth of six dominant Iberian tree species. Within species variation in growth response to repeated dry and wet years was evaluated as a function of individual traits related to resource and water use (diameter at breast height (DBH), wood density (WD) and specific leaf area (SLA)) and tree-to-tree competition across climatically contrasted populations. Furthermore, we assessed how short-term accumulated impacts of the repeated dry and wet years influenced long-term growth performance.

3. All species showed strong short-term growth decreases and enhancements due to repeated dry and wet years. However, patterns of accumulated growth decreases (AcGD) and enhancements (AcGE) across climatically contrasting populations were species-specific. Furthermore, individual trait data were weakly associated to either AcGD or AcGE and the few relevant associations were found for conifers. Intraspecific variations in tree growth responses to repeated climates extremes were large, and not explained by intraspecific variability in SLA and WD. Accumulated impacts of repeated dry and wet years were related to long-term growth trends, showing how the recurrence of climate extremes can determine growth trajectories. The relationships of AcGD and AcGE with long-term growth trends were more common in conifers species.

4. "Synthesis". Repeated climate extremes do not only cause short-term growth reductions and enhancements, but also determine long-term tree growth trajectories. This result shows how repeated droughts can lead to growth decline. Conifers were more susceptible to the accumulated effects of extreme weather events indicating that in the future, more 

by these species.

52

53 Keywords: Dendroecology, drought, forest, functional traits, growth, Iberian Peninsula, 54 wetness. 
56 Climate models forecast an increase in the frequency and intensity of climate extremes such as

57 abnormally dry and wet years (IPCC 2014). Forest vulnerability to drought has been highlighted 58 worldwide (Allen et al., 2010), but the consequences of increasing drought frequency for forest 59 long-term growth dynamics are poorly understood. Most forest responses to drought are studied 60 at short-time interannual scales (Lloret, Keeling \& Sala, 2011; Gazol, Camarero, Anderegg \& 61 Vicente-Serrano, 2017), and miss the long-term perspective (e.g. decades) needed to understand how forest will respond to climate change (Camarero, Gazol, Sangüesa-Barreda, Oliva \& Vicente-

63 Serrano, 2015; Camarero et al., 2018; Peltier \& Ogle, 2019). Extreme wet years also influence 64 growth, and their occurrence between dry years could mitigate the damage caused by droughts 65 (Jiang et al., 2019). However, the importance of wet years has received relatively little attention and our ability to quantify their lasting impact is still limited. Thus, a better understanding of the long-term impact on tree growth caused by repeated dry and wet years should improve our capacity to predict forest vulnerability to climate projections.

Tree rings archive past climate influence on tree performance (Fritts, 1976) which makes radial growth a good proxy to study tree responses to climate change (Marchand et al., 2019). For instance, evaluation of tree-ring growth during and after extreme weather events allows us to examine the stability of forest productivity and tree growth across different spatial and temporal scales (Lloret et al., 2011; Gazol et al., 2017a; Cavin \& Jump, 2017; Sánchez-Salguero et al., 2017a, 2018; Gazol et al., 2018). Furthermore, impacts of drought on tree growth can last for years, resulting in the so called "legacy effects" (Cavin, Mountford, Peterken \& Jump, 2013; Anderegg et al., 2015, Peltier, Fell \& Ogle, 2016; Kannenberg et al., 2019; Gazol et al., 2020).

77 These legacy effects increase as drought episodes become longer and occur closer in time (Peltier $78 \&$ Ogle, 2019). Moreover, high drought impacts on growth might lead to lower growth resilience 79 to the next drought period (Vilà-Cabrera \& Jump, 2019). However, Jiang et al., (2019) suggested 80 that growth responses to extreme wet years might compensate for drought legacy effects. 81 Therefore, repeated wet periods between droughts might buffer trees from pervasive growth 
reductions caused by drought (Matías, González-Díaz \& Jump, 2014). Nevertheless, enhanced growth on mesic sites or during periods of resource surplus (i.e. extreme wetness, competition release) might result in a structural overshoot leading to a higher predisposition to damage during periods of water scarcity (Jump et al., 2017). These potentially conflicting responses raise the question of how the recurrence of dry and wet periods determines growth performance across long time scales, i.e. to what extent repeated dry and wet years impact growth.

Tree growth response to drought varies across a species geographic range (Cavin \& Jump, 2017; Sánchez-Salguero et al., 2018; Vilà-Cabrera \& Jump 2019; Sánchez-Salguero et al., 2017a; Gazol, Rivas, Gutierrez \& Camarero, 2017b). However, patterns of growth resistance to drought across species biogeographical gradients are not yet clear. While some studies point to higher vulnerability to drought of rear-edge (equatorward) tree populations, particularly in xeric sites (Sánchez-Salguero et al., 2017b; Anderegg, Anderegg, Kerr \& Trugman, 2019), others found that core populations are more affected than expected (Cavin \& Jump, 2017; Lloret \& Kitzberger, 2018). One explanation to these disparate results may be that in some rear edges, microclimatic refugia allow some populations to avoid droughts, promoting patchy effects across the distribution range limit rather than a widespread growth decline (Vilà-Cabrera, Premoli \& Jump, 2019; Oldfather, Kilng, Sheth, Emery \& Ackerley, 2019).

Intraspecific responses to extreme climate events may vary based on individual characteristics such as tree size, competition pressure and functional trait variability. For instance, big and/or low competitive trees are prone to drought damage (Nepstad, Tohver, Ray, Moutinho \& Cardinot, 2007). Functional traits such as wood density (WD) and specific leaf area (SLA) have been used to describe plant strategies related to resource acquisition gradients (Wright et al., 2004; Chave et al., 2009; Reich, 2014). These traits have been linked, although weakly, to demography (mortality and growth rates) across species (Martínez-Vilalta, Mencuccini, Vayreda \& Retana, 2010; Greenwood et al., 2017). However, intraspecific trait variation of functional traits such as SLA and WD is high for some species (Fajardo \& Piper, 2011). Whether this intraspecific trait variability is related tree radial growth performance during dry and wet years is unclear. 
Here we evaluate the impact of repeated dry and wet years on tree growth and their relationship with individual functional traits and competitive tree-to-tree interactions. Subsequently, we explore whether such impacts determine long-term growth trends. To this end, we studied growth dynamics in six tree species dominant in Iberian forests across a 26-year period. We selected species growing in contrasting climatic regions, including Eurosiberian (Pinus sylvestris L., Abies alba Mill.) and Mediterranean species (Pinus halepensis Mill., Pinus nigra Arn., Quercus faginea Lam., and Quercus ilex L.). Specifically, we aim to answer the following questions: (i)- Is there a geographical variation in the growth response to repeated dry and wet years? (ii)- do individual functional traits and competitive interactions between neighbour trees influence growth responses to repeated dry and wet years? and (iii)- do short-term growth responses to repeated dry and wet years influence individual growth trends in the long-term? We hypothesize that the impacts of repeated dry and wet years on growth are more prevalent on tree populations located in dry sites (xeric rear edges; cf. Anderegg et al., 2019). Furthermore, we expect that drought year impacts will be more prevalent in trees with strong competitive pressure (Bottero et al., 2017). We also expect relationships of WD and SLA with drought resistance at intraspecific level to follow patterns observed at interspecific level (Greenwood et al., 2017). Finally, we expect that the shortterm growth impacts of repeated dry and wet years will strongly determine growth trajectories across the studied period (see Fig. 1).

\section{Material and methods}

\section{Species and study sites}

We studied six tree species, four gymnosperms of the Pinaceae family (Abies alba Mill., Pinus sylvestris L., Pinus nigra Arn., Pinus halepensis Mill.) and two angiosperms of the Fagaceae family (Quercus faginea Lam. and Quercus ilex L.). A. alba is a montane or subalpine fir widely distributed across Europe, and it reaches its southwestern distribution limit in the Iberian Peninsula, forming abundant populations in the Pyrenees and isolated stands in the Pre-Pyrenees (Supplementary Materials, Fig. S1a). P. sylvestris, has a Eurosiberian distribution that reaches its 
southern distribution at the Iberian Peninsula (Supplementary Materials, Fig. S1b). P. nigra is a

137 pine present across the Mediterranean Basin and Central Europe (Supplementary Materials, Fig.

138 S1c). P. halepensis is a drought-tolerant species distributed across the Mediterranean Basin with its biggest populations located in the Iberian Peninsula (Supplementary Materials, Fig. S2d). $Q$. ilex is an evergreen oak mainly distributed across the Western Mediterranean Basin (Supplementary Materials, Fig. S2f). Q. faginea is a deciduous Mediterranean oak present in the north of Africa and the Iberian Peninsula (Supplementary Materials, Fig. S2e). In Spain, this species forms abundant hybrid populations with Quercus humilis Mill., resulting in Quercus $x$ cerrioides, which does not have clear morphological differentiation from the parental species (See Supplementary Materials). In recognition of the complex taxonomy of these oaks, we take a conservative approach to sampled $Q$. faginea and refer to it here as $Q$. faginea/Q. humilis.

We sampled three populations across the distribution area of each species in the Iberian Peninsula (Supplementary Materials, Fig. S1). We selected populations subjected to contrasting climatic conditions for each species and classified them as dry, intermediate and wet sites. A precipitation gradient between the dry and wet site was present for all species, albeit the range of precipitation between dry and wet sites varied across species (Supplementary Materials, Fig. S2). For Q. ilex and $Q$. faginea $/ Q$. humilis wet and intermediate sites precipitation difference was only $35 \mathrm{~mm}$; however, the wet Collserola coastal site presented mild temperatures conditions (Table 1). Detailed information of each sampled population can be found in Table 1. In the case of $Q$. ilex and $Q$. faginea/Q. humilis, we sampled three sites were both taxa coexisted. For conifers, species composition of the sampled stands ranged from coexistence with several species (both conifers and deciduous) to pure stands (Supplementary Materials, Table S1).

At each site, we randomly selected between 21 and 31 adult, healthy and non supressed individuals and obtained increment cores, functional traits and neighbourhood measures at the individual level as described below.

\section{Individual tree level measures}


To characterize each individual tree, we measured structural and functional variables. For each tree, we measured the four closest neighbours at each cardinal point. Diameter at Breast Height (DBH), distance and species identity of each neighbour were recorded (Table 1). Then, the following competition index $(\mathrm{CI})$ was calculated to assess potential effects of each neighbour depending on its size and distance to focal tree (Forrester, Kohnle, Albrecht \& Bauhus, 2013):

$$
C I=\sum_{i}^{n} \frac{D B H i}{\text { Distance } i-j}
$$

Where $i$ is the neighbour tree and Distance $i-j$ is the distance between the neighbour $(i)$ and focal tree $(j)$.

Furthermore, we measured wood density (WD) and specific leaf area (SLA) for each focal individual (Cornelissen et al., 2003; Supplementary Materials, Fig. S3). To quantify WD, we extracted one wood sample $(5 \mathrm{~cm}$ long) at $1.3 \mathrm{~m}$ using 12 - and 5-mm increment borers for pine and oak species, respectively. We measured wood samples fresh volume following the volume replacement method. We oven dried the samples at $100{ }^{\circ} \mathrm{C}$ for 48 hours before weighting them at $0.01 \mathrm{~g}$ precision. We divided the fresh volume by the dry weight what gave us WD. To quantify SLA, we collected two sun-exposed branches per individual. Once in the laboratory, we separated between 5 and 10 leaves per branch. We measured leaf area in a scanner (Epson Expression 10000XL) using the ImageJ software (Schneider, Rasband \& Elicieri, 2012). Then, we oven dried leaves at $100{ }^{\circ} \mathrm{C}$ for 48 hours and weighted them at $0.01 \mathrm{~g}$ precision. Finally, we calculated SLA as the fresh leaf area divided by the dry leaf weight.

\section{Tree-ring width data}

We cored each focal tree at $1.3 \mathrm{~m}$ height using 5-mm borers. Once in the laboratory, we air dried and mounted the cores on wood supports and sanded them with progressively finer grits until tree rings were clearly recognisable. We performed visual cross dating and measured tree-ring width at $0.01 \mathrm{~mm}$ resolution using a LINTAB-TSAP ${ }^{\mathrm{TM}}$ measuring device (Rinntech, Heidelberg, Germany). We checked the visual cross-dating reliability using the COFECHA software (Holmes, 1983). Due to non-reliable cross-dating, we excluded 16 Q. ilex and 4 Q. faginea/Q. humilis trees 
188 from the following analyses. Common dendrochronological statistics were calculated 189 (Supplementary Materials, Table S2). We transformed tree-ring widths to basal area increment 190 (BAI) to account for geometrical effects of stem enlargement on growth (Biondi \& Qeadan, 191 2008). We calculated BAI using the bai.out function of the $d p l R$ package (Bunn et al., 2018). 192 Furthermore, we standardized BAI as follows: BAI/mean(BAI $\left.\mathrm{Bite}_{\text {se }}\right)$, where mean $\left(\mathrm{BAI}_{\text {site }}\right)$ is the 193 mean BAI in each site. This standardization allowed us to eliminate differences in BAI level between sites.

195 We calculated relative growth decreases (RGD) for drought episodes as the inverse of the ratio of 196 BAI during the drought year $\left(B A I_{d r o u g h t}\right)$ by the mean BAI of the four preceding years $\left(B A I_{\text {pre- }}\right.$ 197 drought):

$$
R G D=1 /\left(B_{\text {Arought }} / B A I_{\text {pre-drought }}\right)
$$

199 Note, that this is the inverse of the resistance index defined by Lloret et al., (2011). Then, we computed the accumulated growth decrease (AcGD) of all the studied droughts as the sum of the RGD of each drought period:

$$
A c G D=R G D_{1}+\ldots+R G D_{n}
$$

AcGD quantifies the drought impact on tree growth across longer periods of time by reflecting cumulative RGD effects. Furthermore, we also calculated the relative growth enhancement (RGE) for the wet years as the ratio of BAI during the wet $\left(B A I_{\text {wet }}\right)$ and the mean BAI values of the four years preceding the wet year $\left(B A I_{\text {pre-wet }}\right)$ :

$$
R G E=B A I_{\text {wet }} / B A I_{\text {pre-wet }}
$$

209 The accumulated growth enhancement (AcGE) of the recurrent wet years was then calculated as 210 the sum of the RGE of each wet period:

$$
A c G E=R G E_{1}+\ldots+R G E_{n}
$$


212 RGE can be interpreted as a measure of tree capacity to grow when resources are available (in 213 this case high water availability). Both, AcGD and AcGE were calculated at individual tree level.

214 In cases when RGD or RGE for a single event were lower than 1 (i.e. no decrease/increase of 215 growth), we set the value to 0 to account for the lack of response of the tree to that event 216 (Supplementary Materials, Fig. S4). We also calculated AcGD and AcGE using different 217 reference periods (from 1 to 7 years). This was done to evaluate the influence of the reference period in the calculation of RGD and RGE and thus on further results.

\section{Selection of dry and wet years}

220

To evaluate the effect of recurrent droughts on tree growth performance we focused on the period from 1990 to 2016. We downloaded series of the Standardized Precipitation Evapotranspiration Index (hereafter SPEI) at 1.1-km² resolution (Vicente-Serrano et al., 2017) for each studied site. The SPEI reflects the cumulative drought stress experienced by vegetation as it is calculated as a function of temperature and precipitation data (Vicente-Serrano, Begueria \& Lopéz-Moreno, 2010). We selected three common droughts (1994-1995, 2005 and 2012) for all sites. To select these common years, we used the following criterion: in all sites, SPEI had to be below the lower $30 \%$ values of the 1990-2016 period for at least one of both, September 6-month scale or September 12-month scale. To select wet years, we used the following criterion: in all sites SPEI had to be above the higher 30\% values of 1990-2016 period for at least one of both, September 6 or September 12-month resolution. The years 1997, 2008 and 2013 were selected as wet years. More detailed information on methods for selection of dry and wet years can be found in Supplementary Materials.

\section{Statistical analyses}

To evaluate the effects of recurrent dry and wet years on tree growth performance during the 1990-2016 period we used the following analyses. First, to evaluate tree structural and functional characteristics and site effects on growth response to repeated dry and wet years we fitted a set of 
species-specific generalized linear models. For each species, AcGD and AcGE were modelled as function of site, DBH, CI, SLA and WD (all variables were log transformed prior to the analyses) using the following formulae:

$A c G D=\beta_{0}+\beta_{1} *$ site $+\beta_{2} * \log (D B H)+\beta_{3} * \log (C I)+\beta_{4} * \log (S L A)+\beta_{5} * \log (W D)+\varepsilon$

$A c G E=\beta_{0}+\beta_{1} *$ site $+\beta_{2} * \log (D B H)+\beta_{3} * \log (C I)+\beta_{4} * \log (S L A)+\beta_{5} * \log (W D)+\varepsilon$

Where $\beta_{0}$ represents the overall intercept and $\beta_{1}$ to $\beta_{5}$ the parameters adjusting each predictor variable and $\varepsilon$ the error term.

Then, to evaluate the effect of recurrent dry and wet years on growth performance across longer period we used linear mixed-effect models. Log-transformed BAI for the 1990-2016 was modelled as a function of calendar year, AcGD, AcGE (as proxies of cumulative dry and wet year impact) and the interaction of calendar year with AcGD and AcGE.

$$
\begin{gathered}
\log \left(B A I_{i}\right)=\beta_{0}+\alpha_{0 i}+\beta_{1} * \text { Year }_{i}+\beta_{2} * A c G D_{i}+\beta_{3} * A c G E_{i}+\beta_{4} *\left(\text { Year }_{i} * A c G D_{i}\right)+\beta_{5} *\left(\text { Year }_{i} *\right. \\
\left.A c G E_{i}\right)+\varepsilon_{i}
\end{gathered}
$$

Where $i$ represents individual tree identity, $\beta_{0}$ the overall intercept and $\beta_{1}$ to $\beta_{5}$ the parameters adjusting fixed effects, $\alpha_{0}$ the random effects on the intercept associated with tree. An error term $\varepsilon_{i}$ with a first-order temporal autocorrelation $[\mathrm{AR}(1)]$ was also included in the model. Log transformation was applied to standardized BAI to achieve a normal distribution. The inclusion of the factor "Year" allows to determine growth trajectories across the studied period. The inclusion of AcGD and AcGE was used to detect the cumulative effects of recurrent dry and wet years on tree growth trajectories (interaction Year* AcGD/AcGE). We applied this model to each species ( 6 species) and at population level (18 models, one per species and site). Mixed models were fitted using the package $n l m e$ (Pinheiro et al., 2019). Finally, the marginal $\mathrm{R}^{2}\left(\mathrm{R}^{2} \mathrm{~m}\right.$, variance explained by fixed effects) and conditional $R^{2}\left(R^{2} c\right.$, variance explained by fixed and random effects) were calculated following Nakagawa et al., (2017). Furthermore, we evaluated the fit of the models by graphical inspection of the residuals and the fitted values. We performed all analyses in R environment (R Project Team, 2018). 
264 All models presented here use a reference period of 4 years to calculate AcGD and AcGE, results 265 using other reference period (from 1 to 7 years) are presented in the Supplementary Materials, 266 Figs. S5 and S6. To perform the abovementioned analyses some trees had to be discarded due to 267 their young age (5 Q. ilex; 7 Q. faginea/Q. humilis; 13 P.halpensis; 3 P. nigra;13 P. sylvestris and 2689 A. alba) which left us with a total sample of 468 trees (71 Q. ilex, 79 Q. faginea/Q. humilis, 77 269 P. halpensis, 87 P. nigra, 77 P. sylvestris and 77 A. alba).

Results

\section{Growth impacts}

Accumulated growth decreases (AcGD) and enhancements (AcGE) due to recurrent dry and wet years, occurred for all tree species (Fig. 2). Site differences in AcGD and AcGE were evident in all species except AcGE in P. nigra (Table 2, Fig. 2). However, AcGD/AcGE differences across populations with contrasting climate conditions were species-specific (Fig. 2). The impact of recurrent dry years on growth was higher in dry populations of $P$. sylvestris and $P$. halepensis, the intermediate population of $P$. nigra, the wet population of $Q$. ilex, both dry and wet populations of $Q$. faginea/Q. humilis, and intermediate population of $A$. alba (Fig. 2). The impact of recurrent wet years on growth was also species specific. For example, $Q$. ilex presented the higher growth enhancement in intermediate sites (Fig. 2) whilst this was observed for P. sylvestris, Q. faginea/Q. humilis and A. alba on the dry site and P. halepensis at both dry and intermediate sites (Fig. 2).

The influence of functional traits and competition on AcGD and AcGE was weak and species-specific (Table 2). Conifer species were affected by structural and functional variables (Table 2.). AcGD of $P$. nigra was higher in big trees suffering high competition (Table 2). AcGE of A. alba was negatively related to CI and DBH (Table 2). AcGE of P. sylvestris and A. alba was 
Successive dry and wet years determined growth trends across the study period (Fig. 3a, b). In all species but Q. ilex, trees suffering higher cumulative drought impact (i.e. higher AcGD) showed more negative growth trends (negative significant interaction year* AcGD, Table 3, Fig. 3a). In all species, trees that grew more during wet years presented the most positive growth trends (positive significant interaction year * AcGE, Table 3, Fig. 3b). For $P$. halepensis and $P$. sylvestris, the AcGD-growth trend relationship was influenced by the dry population showing extreme growth reductions (Fig. 2) while, for the other species, populations with higher AcGD did not present the more negative growth trends (Fig. 2).

Differences in AcGD and AcGE also resulted in different growth trends at the withinpopulation (Table 3, Fig. 4). Recurrent dry years resulted in negative growth trends (significant negative year* AcGD interaction; Table 3, Fig 4) in all conifer populations except at the dry site of $P$. sylvestris (Table 3, Fig. 4). The effect of successive wet years on growth trends was present (significant year * AcGE interaction; Table 3) in two or more populations of all species (Table 3, Fig. 4).

\section{Discussion}

Our results show how successive extreme dry and wet conditions strongly influence tree growth. Widespread accumulated growth decreases (AcGD) and enhancements (AcGE) after three successive dry and wet years were present for all species. These AcGD and AcGE were related to long term growth trajectories (Fig. 1). As a consequence, the three drought and wet years studied determined the trajectory of tree performance throughout the 1990-2016 period. This pattern was more prevalent for conifers, although with variation between and within populations (Fig. 2, 3 and 4).

\section{Geographical variation of AcGD and AcGE}


315 Geographical variation in growth responses to extreme weather events depends on several factors,

316 which result in species-specific responses across the studied climatic and biogeographic gradients.

317 First, topographical complexity generates microclimatic conditions that can decouple tree

318 response and macroclimatic weather events (Adams, Barnard \& Loomis, 2014). Non-climatic environmental conditions (e.g. soil texture and nutrients) may exacerbate this disparity between macroclimatic conditions and growth response to dry and wet years (Lévesque, Walthert \& Weber, 2016). For instance, here we only found two species, $P$. sylvestris and P. halepensis that presented higher AcGD on the dry sites (Fig. 2). Besides, differences in biotic conditions and species-specific traits can result in different performance across species growing under the same regional climate conditions (Battipaglia, Saurer, Cherubini, Siegwolf \& Cortufo, 2009; Friedrichs et al., 2009). For example, different growth phenology may result in contrasted responses during dry and wet years. In this sense, $Q$. ilex and $Q$. faginea/Q. humilis coexist in the same sites but showed different responses to repeated dry years in the dry site and to repeated wet years in all sites (Fig. 2). $Q$. ilex is able to grow in early-summer and fall, whereas most of the $Q$. faginea/Q.humilis radial growth occurs in spring and summer (Montserrat-Martí et al., 2009) suggesting higher drought vulnerability to summer water shortage in the latter. Furthermore, different strategies related to water use result in different responses to drought under the same conditions (Anderegg \& HilleRisLambers, 2016). In this study, P. halepensis populations which were sampled in the same or nearby $Q$. ilex and $Q$. faginea/Q. humilis sites presented different responses to repeated dry and wet years which could be explained by differences in water use (Fig. 2). Therefore, site, population and even tree specific characteristics (i.e, population density, age, community compositions...) can be related to different response to dry and wet years, exacerbating or mitigating predictions solely made by macroclimatic conditions. Furthermore, precipitation variability between dry and wet sites differed across tree species, which may contribute to the lack of common geographical pattern of AcGD/AcGE across species. This suggests that wider gradients across the species distribution range should be used. 
Empirical evidence indicates that the occurrence of drought years strongly reduces radial growth (Zang, Hartl-Meier, Dittmar, Rothe \& Menzel, 2014; Martínez-Vilalta, López, Loepfe \& Lloret, 2012; Gazol et al., 2017a; Cavin \& Jump, 2017; Serra-Maluquer, Mencuccini \& Martínez-Vilalta, 2018; Kannenberg et al., 2019). However, which individual traits and stand-level abiotic and biotic factors are related to these growth reductions is less clear (Kannenberg, Schwalm \& Anderegg 2020). We found weak, species-specific relationships between functional traits (SLA) and competition intensity and/or tree dominance (competition index and tree size) with AcGD and AcGE of successive dry and wet years. Our expectations based on tree size and competition (higher response to water scarcity in bigger trees and higher growth reductions but lower enhancements under highly competitive pressure) were only found on AcGD for P. nigra and AcGE for $A$. alba (Table 2). High resource acquisitive strategies (high SLA, low WD) were only related to AcGD and AcGE in two species (P. sylvestris and A. alba). However, only the patterns observed for A. alba supported the idea that more resource acquisitive strategy (high SLA) would lead to higher drought damage (Table 2, Greenwood et al., 2017). Recent studies suggest that functional traits have low potential to predict variability in resource use strategy at the withinspecies scale (Anderegg et al., 2018; Rosas et al., 2019). For instance, Fajardo $(2016,2019)$ found no relationship between WD and growth rates or competition ability in Nothofagus pumilio. Our results agree with these studies, and indicate that variability of WD and SLA are poorly related to growth responses to extreme events at the intraspecific level, although they can determine to some degree growth seasonality (Camarero, 2019). It is also possible that the absence of relationships between CI, tree size and the measured functional traits with AcGD and AcGE are due to differences in the temporal resolution of the data. We evaluate present information (CI and traits) and changes in this data through the study period (i.e. differences in stand structure) may influence lack of patterns in our results. Furthermore, hydraulic traits may be more informative than WD or SLA, however, such data is difficult to obtain in a sample size as ours, but further research is needed in this direction (Hartmann et al., 2018). 
When within-species results are compared across species, the relationships of AcGD and AcGE with structural and functional variables are only present in gymnosperms (Table 2). Hence, our expectations of the relationships between growth responses to extreme events and structural and functional characteristics were only present in conifers. In the Iberian Peninsula variability in tree growth response to drought (Gazol et al., 2018), growth responses to climate and competition (Gómez-Aparicio, García-Valdés, Ruiz-Benito \& Zavala, 2011) and functional traits (Poorter, Lianes, Moreno de las Heras \& Zavala, 2012; Carnicer, Barbeta, Sperlich, Coll, \& Peñuelas, 2013; Vilà-Cabrera, Martínez-Vilalta \& Retana, 2015) reflect differences between Pinaceae and Fagaceae species, mainly pine and oaks. As a result, differences in the incidence of structural and functional variables on growth response to extreme events between these groups was expectable.

\section{Relationships between AcGD, AcGE and growth trends}

Extreme weather impacts on tree growth can last for several years causing legacies (Anderegg et al., 2015, Jiang et al., 2019), and if they occur several times, their effects might accumulate affecting long-term tree performance. For instance, Peltier \& Ogle (2019) showed how successive droughts resulted in larger legacy effects on tree-ring growth of Pinus ponderosa than a single drought. Our results agree with this previous evidence, i.e. accumulated growth reductions of successive droughts resulted in negative long-term growth trends (Figs. 3 and 4). The fact that successive droughts ended up reducing the growth trends of populations with overall positive, negative, and neutral growth (Figs. 2 and 4) indicates that recurrent drought impacts affect tree performance independently of the mean population growth trends. This finding suggests widespread vulnerability to growth decline, which has been identified as an indicator of reduced health and increased probability of tree death (Camarero et al., 2015; Cailleret et al., 2017). Furthermore, the accumulated effects of repeated droughts could also generate a decrease in growth resistance across time, a pattern already seen in some pine species in the studied area (Serra-Maluquer et al., 2018, Gazol et al., 2018). Moreover, repeated wet years may result in positive or stable growth trends (Figs. 2 and 3), which in fact could potentially reverse negative trends caused by repeated dry years (Jiang et al., 2019). However, caution must be taken as growth 
enhancement due to water surplus may be overestimated due to competition releases after

397 drought-induced tree death, a process observed in the study area (Galiano, Martínez-Vilalta \& 398 Lloret ,2010; Camarero et al., 2015). Finally, the effects of repeated dry and wet years on growth trends were predominant in conifers, which is in accordance with studies reporting higher legacy effects in these species compared to angiosperms (e.g. oaks) after both dry and wet years (Anderegg et al., 2015; Jiang et al., 2019).

402

403

Low growth rates and declining growth trends are observed in dead individuals when comparing them to living conspecifics in the same populations (Hereş et al., 2012, Camarero et al., 2015, Cailleret et al., 2017). Recently, De Soto et al., (2020) reported that dead trees presented lower resilience (short-term impact) to past drought events than their surviving neighbours. Here we show that these two growth responses potentially leading to tree death, i.e. short-term growth reductions and long-term negative growth trends, are related and that the accumulation of successive droughts impacts may increase the declining growth trends.

Climate projections indicate that the frequency and intensity of extreme climate events will increase. These will cause higher impacts on tree growth and as a consequence determine their future growth trajectories. If the frequency and severity of extreme drought events increase, their accumulated impacts will be higher, which will lead to increasingly widespread growth decline, dieback and, potentially, tree death. The intraspecific growth and trait variability presented here suggests that, to accurately predict when and where the effects of successive extremes climate events will be more pervasive, better knowledge on which site and individual characteristics prevent drought vulnerability is needed.

\section{Acknowledgments}

We thank Josep Maria Espelta (CREAF) for the help in the sampling of Collserola site. XSM is supported by a $\mathrm{PhD}$ grant (FPI) from the Spanish Ministery of Economy, Industry and Competitiveness (BES-2016-077676). EG and GSB are supported by a Spanish Ministry of 
422 Economy, Industry and Competitiveness Postdoctoral grant (IJCI-2017-32511 and FJCI 2016423 30121; FEDER funds). AVC was supported by the $50^{\text {th }}$ Anniversary Fellowship Program of the 424 University of Stirling and by a Juan de la Cierva-Incorporación grant (IJC2018-038508-I) from 425 the Spanish Ministry of Science, Innovation and Universities. This study was funded by the 426 projects CGL2015-68186-C2-1-R and RTI2018-096884-B-C31 (Spanish Ministry of Science, 427 Innovation and Universities). RSS, AG and JJC were also supported by project LMP242_18 and 428 VULBOS project (UPO-1263216) from the FEDER funds 2014-2020 from Aragón and 429 Andalusia regional governments, respectively. We thank Ayuntamiento de Leoz for permitting 430 access to the study area in Sansoain.

432 Author's contribution

433 XSM, EG, JJC and AG designed the study. XSM, EG, JJC, AG, RSS, GSB and JBI collected and 434 processed the data. XSM, AVC \& ASJ analysed and interpreted the data. XSM lead the writing 435 of the manuscript with significant contributions of all authors.

\section{Data availability}

437 Data available from the Dryad Digital Repository: https://doi.org/10.5061/dryad.dfn2z350f 438 (Serra-Maluquer et al., 2020) 
440 Adams, H.R., Barnard, H.R., \& Loomis, A.K. (2014). Topography alters tree growth-climate

441 relationships in a semi-arid forested catchment. Ecosphere 5: 1-16. 442 https://dx.doi.org/10.1890/ES14-00296.1

443 Allen, C.D., Macalady, A.K., Chenchouni, H., Bachelet, D., McDowell, N., Vennetier, M., ... 444 Cobb, N. (2010). A global overview of drought and heat-induced tree mortality reveals emerging 445 climate change risks for forests. Forest Ecology and Management, 259: 660-684. 446 https://doi.org/10.1016/j.foreco.2009.09.001

447 Anderegg., L.D.L., \& HilleRisLambers, J. (2016). Drought stress limits the geographic ranges of 448 two tree species via different physiological mechanisms. Global Change Biology, 22: 1029-1045. 449 https://doi.org/10.1111/gcb.13148

450 Anderegg, L.D.L., Berner, L.T., Badgley, G., Sethi, M.L., Law, B.E., \& HilleRisLambers, J. 451 (2018). Within-species patterns challenges our understanding of the leaf economics spectrum. 452 Ecology Letters 21: 734-744. https://doi.org/10.1111/ele.12945

453 Anderegg, W.R.L., Anderegg, L.D.L., Kerr, K.L., \& Trugman, A.T. (2019). Widespread drought454 induced tree mortality at dry range edges indicates climate stress exceeds species' compensating 455 mechanisms. Global Change Biology, 25: 3793-3802. https://doi.org/10.1111/gcb.14771

456 Anderegg, W.R.L., Schwalm, C., Biondi, F., Camarero, J.J., Koch, G., Litvak, M., ... Pacala, S. 457 (2015). Pervasive drought legacies in forest ecosystems and their implications for carbon cycle 458 models. Science, 349: 528-532. https://doi.org/10.1126/science.aab1833

459 Battipaglia, G., Saurer, M., Cherubini, P., Siegwolf, R.T.W., \& Cotrufo, M.F. (2009). Tree rings 460 indicate different drought resistance of a native (Abies alba Mill.) and a nonnative (Picea abies 461 (L.) Karst.) species co-occurring at a dry site in the Southern Italy. Forest Ecology and 462 Management, 257, 820-828. https://doi.org/10.1016/j.foreco.2008.10.015 
463 Biondi, F. \& Qeadan, F. (2008). A theory-driven approach to tree-ring standardization: defining

464 the biological trend from expected basal area increment. Tree-Ring Research, 64: 81-96. 465 https://doi.org/10.3959/2008-6.1

466 Bottero, A., D’Amato, A.W., Palik, B.J., Bradford, J.B., Fraver, S., Battaglia, M.A., \& Asherin, 467 L.A. (2017). Density-dependent vulnerability of forest ecosystems to drought. Journal of Applied 468 Ecology, 54: 1605-1614. https://doi.org/10.1111/1365-2664.12847

469 Bunn, A., Korpela, M., Biondi, F., Campelo, F., Mérian, P., Qeadan, F., Zang, C., (2020). dplR:

470 Dendrochronology Program Library in R. R package version 1.7.1. https://CRAN.R471 project.org/package $=\mathrm{dp} 1 \mathrm{R}$

472 Cailleret, M., Jansen, S., Robert, E.M.R., Desoto, L., Aakala, T., Antos, J.A., ... Martínez-Vilalta, 473 J. (2017). A synthesis of radial growth patterns preceding tree mortality. Global Change Biology, 474 23: 1675-1690. https://doi.org/10.1111/gcb.13535

475 Camarero, J.J. (2019). Linking functional traits and climate-growth relationships in 476 Mediterranean species through wood density. IAWA Journal 40, 215-240. 477 https://doi.org/10.1163/22941932-40190225.

478 Camarero, J.J., Gazol, A., Sangüesa-Barreda, G., Oliva, J., \& Vicente - Serrano, S. (2015). To

479 die or not to die: early warnings of tree dieback in response to a severe drought. Journal of 480 Ecology, 103: 44-57. https://doi.org/10.1111/1365-2745.12295

481 Camarero, J.J., Gazol, A., Sangüesa-Barreda, G., Cantero, A., Sánchez-Salguero, R., Sánchez482 Miranda, A., ... Ibáñez, R. (2018). Forest growth response to drought at short- and long-term 483 scales in Spain: squeezing the stress memory from tree rings. Frontiers in Ecology and Evolution, 484 6. https://doi.org/10.3389/fevo.2018.00009

485 Carnicer, J., Barbeta, A., Sperlich, D., Coll, M., \& Peñuelas, J. (2013). Contrasting trait 486 syndromes in angiosperms and conifers are associated with different responses of tree growth to 
temperature on a large scale. Frontiers in plant Science, 4: 409. https://doi.org/10.3389/fpls.2013.00409

489 Cavin, A., \& Jump, A.S. (2017). Highest drought sensitivity and lowest resistance to growth 490 suppression are found in the range core of the tree Fagus sylvatica L. not the equatorial range 491 edge. Global Change Biology, 23: 362-379. https://doi.org/10.1111/gcb.13366

492 Cavin, L., Mountford, E. P., Peterken, G.F., \& Jump, A.S. (2013). Extreme drought alters 493 competitive dominance within and between tree species in a mixed forest stand. Functional 494 Ecology, 27: 1424-1435. https://doi.org/10.1111/1365-2435.12126

495 Chave, J., Coomes, D., Jansen, S., Lewis, S.L., Swenson, N.G., \& Zanne, A.E. (2009). Towards 496 a worldwide wood economics spectrum. Ecology Letters, 12: 351-366. 497 https://doi.org/10.1111/j.1461-0248.2009.01285.x

498 Cornelissen, J.H.C., Lavorel, S., Garnier, E., Díaz, S., Buchmann, N., Gurvich, D.E., ... Poorter, 499 H. (2003). A handbook of protocols for standardised and easy measurement of plant functional 500 traits worldwide. Australian Journal of Botany, 51: 335-380. https://doi.org/10.1071/BT02124

501 De Soto, L., Cailleret, M., Sterck, F., Jansen, S., Kramer, K., Robert, E.M.R., ... Martínez-Vilalta, 502 J. (2020). Low growth resilience to drought is related to future mortality risk in trees. Nature 503 Communications, 11: 545. https://doi.org/10.1038/s41467-020-14300-5

504 Fajardo, A. (2016). Wood density is a poor predictor of competitive ability among individuals of 505 the same species. Forest Ecology and Management, 372: 217-225. 506 https://doi.org/10.1016/j.foreco.2016.04.022

507 Fajardo, A. (2018). Insights into intraspecific wood density variation and its relationship with 508 growth, height and elevation in a treeline species. Plant Biology, 20: 456-464. 509 https://doi.org/10.1111/plb.12701 
510 Fajardo, A. \& Piper, F.I. (2011). Intraspecific trait variation and covariation in a widespread tree

511 species (Nothofagus pumlio) in southern Chile. New Phytologist, 189: 259512 271. https://doi.org/10.1111/j.1469-8137.2010.03468.x

513 Forrester, D.I., Kohnle, U., Albrecht, A.T., \& Bauhus, J. (2013). Complemetarity in mixed514 species stands of Abies alba and Picea abies varies with climate, site quality and stand density. 515 Forest Ecology and Management, 304: 233-242. https://doi.org/10.1016/j.foreco.2013.04.038

516 Fritts, H.C. (2001). Tree rings and Climate. Cladwell, USA: Balckburn Press.

517 Friedrichs, D.A., Trouet, V., Büntgen, U., Frank, D.C., Esper, J., Neuwirth, B., \& Löffler, J. 518 (2009). Species-specific climate sensitivity of tree growth in the central-west Germany. Trees, 519 23: 729. https://doi.org/10.1007/s00468-009-0315-2

Galiano, G., Martínez-Vilalta, J., \& Lloret, F. (2010). Drought-induced multifactor decline of scots pine in the Pyrenees and potential vegetation change by expansion of co-occuring oak species. Ecosystems, 13: 978-991. https://doi.org/10.1007/s10021-010-9368-8

523 Gazol, A., Camarero, J.J., Anderegg, W.R.L., \&Vicente-Serrano, S.M. (2017a). Impacts of 524 drought on the growth resilience of Northern hemisphere forests. Global Ecology and 525 Biogeography, 26: 166-176. https://doi.org/10.1111/geb.12526

526 Gazol, A., Ribas, M., Gutiérrez, E., \& Camarero, J.J. (2017b). Aleppo pine forest from across 527 Spain show drought-induced growth decline and partial recovery. Agricultural and Forest 528 Meteorology, 232: 186-194. https://doi.org/10.1016/j.agrformet.2016.08.014

529 Gazol, A., Camarero, J.J., Vicente-Serrano, S.M., Sánchez-Salguero, S.M., Gutiérrez, E., De Luis, 530 M., ... Galván, J. (2018). Forest resilience to drought varies across biomes. Global Change 531 Biology 24: 2143-2158. https://doi.org/10.1111/gcb.14082

532 Gazol, A., Camarero, J.J., Sánchez-Salguero, R., Vicente-Serrano, S., Serra-Maluquer, X., 533 Gutiérrez, E., ... Galván, J. (2020). Drought legacies are short, prevail in dry conifer forests and 
depend on growth variability. Journal of Ecology, 108: 2473-2484. https://doi.org/10.1111/13652745.13435

536 Gómez-Aparicio, L., García-Valdés, R., Ruiz-Benito, P., Zavala, M.A. (2011). Disentangling the 537 relative importance of climate, size and competition on tree growth in Iberian forests: implications 538 for forest management under global change. Global Change Biology, 17: 2400-2414. 539 https://doi.org/10.1111/j.1365-2486.2011.02421.x

540 Greenwood, S., Ruiz-Benito, P., Martínez-Vilalta, J., Lloret, F., Kitzberger, T., Allen, C.D., ... 541 Jump, A.S. (2017). Tree mortality across biomes is promoted by drought intensity, lower wood 542 density and higher specific leaf area. Ecology Letters, 20: 539-553. 543 https://doi.org/10.1111/ele. 12748

544 Hartmann, H., Moura, C.F, Anderegg, W.R.L., Ruehr, N.K., Salmon, Y., Allen, C.D., ... O’Brien, 545 M. (2018). Research frontiers for improving our understanding of drought- induced tree and forest 546 mortality. New Phytologist, 218: 15-28. ttps://doi.org/10.1111/nph.15048

547 Hereş, A.M., Martínez-Vilalta, J.M., \& López, B.C. (2012). Growth patterns in relation to 548 drought-induced mortality at two Scots pine (Pinus sylvestris L.) sites in NE Iberian Peninsula. 549 Trees, 26: 621-630. https://doi.org/10.1007/s00468-011-0628-9

550 Holmes, R.L. (1983). Computer-assisted quality control in tree-ring dating and measurement. 551 Tree-Ring Bulletin, 43: 69-78.

552 IPCC, 2014: Climate Change 2014: Synthesis Report. Contribution of Working Groups I, II and 553 III to the Fifth Assessment Report of the Intergovernmental Panel on Climate Change [Core 554 Writing Team, R.K. Pachauri and L.A. Meyer (eds.)]. IPCC, Geneva, Switzerland, 151 pp.

555 Jiang, P., Liu, H., Piao, S., Ciais, P., Wu, X., Yin, Y., \& Wang, H. (2019). Enhanced growth after 556 extreme wetness compensates for post-drought carbon loss in dry forests. Nature 557 Communications, 10: 195. https://doi.org/10.1038/s41467-018-08229-z 
558 Jump, A.S., Ruiz-Benito, P., Greenwood, S., Allen, C.D., Kitzberger, T., Fensham, R., ... Lloret,

559 F. (2017). Structural overshoot of tree growth with climate and the global spectrum of drought-

560 induced forest dieback. Global Change Biology, 23: 3742-3757.

561 https://doi.org/10.1111/gcb.13636

562 Kannenberg, S.A., Maxwell, J.T., Pederson, N., D’Orangeville, J., Ficklin, D.L., \& Phillips, R.P.

563 (2019). Drought legacies are dependent on water table depth, wood anatomy and drought timing

564 across the eastern US. Ecology Letters, 22: 119-127. https://doi.org/10.1111/ele.13173

565 Kannenberg, S.A., Schwalm, C.R., \& Anderegg, W.R.L. (2020). Ghosts of the past: how drought

566 legacy effects shape forest functioning and carbon cycling. Ecology Letters, 23: 891-901.

567 https://doi.org/10.1111/ele.13485

568 Lévesque, M., Walthert, L., \& Weber, P. (2016). Soil nutrients influence growth response of

569 temperate tree species to drought. Journal of Ecology, 104: 377-387.

570 https://doi.org/10.1111/1365-2745.12519.

571 Lloret, F., \& Kitzberger, T. (2018). Historical and event-based bioclimatic suitability predicts

572 regional forest vulnerability to compound effects of severe drought and bark beetle infestation.

573 Global Change Biology, 24: 1952-1964. https://doi.org/10.1111/gcb.14039

574 Lloret, F., Keeling, E.G., \& Sala, A. (2012). Components of tree resilience: effects of successive 575 low growth episodes in old ponderosa pine forests. Oikos, 120: 1909-1920. 576 https://doi.org/10.1111/j.1600-0706.2011.19372.x

577 Marchand, W., Girardin, M.P., Hartmann, H., Gauthier, S., \& Bergeron, Y. (2019). Taxonomy, 578 together with ontogeny and growing conditions, drives needleleaf species' sensitivity to climate

579 in boreal North America. Global Change Biology, 25: 2793-

580 2809. https://doi.org/10.1111/gcb.14665 
581 Martínez-Vilalta, J., López, B.C., Loepfe, L., \& Lloret, F. (2012). Stand- and tree-level 582 determinants of the drought response of Scots pine radial growth. Oecologia, 168: 877-888. 583 https://doi.org/10.1007/s00442-011-2132-8

584 Martínez-Vilalta, J., Mencuccini, M., Vayreda, J., \& Retana, J. (2010). Interspecific variation in 585 functional traits, not climatic differences among species ranges, determines demographic rates 586 across 44 temperate and Mediterranean tree species. Journal of Ecology, 98: 1462-1475. 587 https://doi.org/10.1111/j.1365-2745.2010.01718.x

Matías, L., González-Díaz, P., \& Jump A.S. (2014). Larger investment in roots in southern range589 edge populations of Scots pines is associated with increased growth and seedling resistance to extreme drought in response to simulated climate change. Environmental and Experimental Botany, 105: 32-38. https://doi.org/10.1016/j.envexpbot.2014.04.003 Montserrat-Martí, G., Camarero, J. J., Palacio, S., Pérez-Rontomé, C., Milla, R., Albuixech, J. and Maestro, M. (2009). Summer-drought constrains the phenology and growth of two coexisting Mediterranean oaks with contrasting leaf habit: implications for their persistence and reproduction. Trees, 23: 787-799. https://doi.org/10.1007/s00468-009-0320-5

Nakagawa, S., Johnson, P.C.D., \& Schielzeth, H. (2017). The coefficient of determination $\mathrm{R}^{2}$ and intra-class correlation coefficient from generalized linear mixed-effects models revisited and expanded. Journal of The https://doi.org/10.1098/rsif.2017.0213

600 Nepstad, D.N., Tohver, I.M., Ray, D., Moutinho, P. \& Cardinot, G. (2007). Mortality of large 601 trees and lianas following experimental drought in an amazon forest. Ecology, 88: 2259-2269. 602 https://doi.org/10.1890/06-1046.1

603 Ninyerola, M., Pons, X., \& Roure, J.M. (2005). Atlas Climático Digital de la Península Ibérica. 604 Metodología y aplicaciones en bioclimatología y geobotánica. ISBN 932860-8-7. Universidad 605 Autónoma de Barcelona, Bellaterra. 
606 Oldfather, M.F., Kling, M,M., Sheth, S.N., Emery, N.C., \& Ackerly, D.D. (2019). Range edges

607 in heterogeneous landscapes: Integrating geographic scale and climate complexity into range 608 dynamics. Global Change Biology, 26: 1055-1067. https://doi.org/10.1111/gcb.14897

609 Peltier, D.M.P., Fell, M., \& Ogle, K. (2016). Legacy effects of drought in the southwestern United 610 States: A multi-species synthesis. Ecological Monographs, 86: 312-326. 611 https://doi.org/10.1002/ecm.1219

612 Peltier, D.M.P., \& Ogle, K. (2019). Legacies of more frequent drought in ponderosa pine across 613 the western United States. Global Change Biology, 25: 3803614 3816. https://doi.org/10.1111/gcb.14720

615 Pinheiro J., Bates D., DebRoy S., Sarkar D., R Core Team (2019). nlme: Linear and Nonlinear 616 Mixed Effects Models. R package version 3.1-117.

617 Poorter, L., Lianes, E., Moreno de las Heras, M., \& Zavala, M.A. (2012). Architecture of Iberian 618 canopy tree species in relationship to Wood density, shade tolerance and climate. Plant Ecology, 619 213: 707-722. https://doi.org/10.1007/s11258-012-0032-6

620 R Core Team (2018). R: A language and environment for statistical computing. R Foundation 621 for Statistical Computing, Vienna, Austria. https://www.R-project.org/.

622 Reich, P.B. (2014). The world-wide "fast-slow" plant economics spectrum: a traits manifesto. 623 Journal of Ecology, 102: 275-301. https://doi.org/10.1111/1365-2745.12211

624 Rosas, T., Mencuccini, M., Barba, J., Cochard, H., Saura-Mas, S., \& Martínez-Vilalta, J. (2019). 625 Adjustments and coordination of hydraulic, leaf and stem traits along a water availability gradient. 626 New Phytologist, 223: 632-646. https://doi.org/10.1111/nph.15684

627 Sánchez-Salguero, R., Camarero, J.J, Carrer, M., Gutiérrez, E., Alla, A.Q., Andreu-Hayles, L., ... 628 Linares, J.C. (2017a). Climate extremes and predicted warming threaten Mediterranean Holocene 
629 firs forests refugia. Proceedings of the National Academy of Sciences of the USA, 114(47), 630 E10142-E10150. https://doi.org/10.1073/pnas.1708109114

631 Sánchez-Salguero, R., Camarero, J.J., Gutiérrez, E., González-Rouco, F., Gazol, A., Sangüesa632 Barreda, G., ... Seftigen, K., (2017b). Assessing forest vulnerability to climate warming using 633 process-based model of tree growth: bad prospects for rear-edges. Global Change Biology, 23: 634 2705-2719. https://doi.org/10.1111/gcb.13541

635 Sánchez-Salguero, R., Camarero, J.J., Rozas, V., Génova, M., Olano, J.M., Arzac, A., ... Linares, 636 J.C. (2018). Resist, recover or both? Growth plasticity in response to drought is geographically 637 structured and linked to intraspecific variability in Pinus pinaster. Journal of Biogeography, 45: 638 1126-1139. https://doi.org/10.1111/jbi.13202

639 Schneider, C.A., Rasband, W.S., \& Eliceiri, K. W. (2012). NIH image to ImageJ: 25 years of 640 image analyses: Nature methods 9, 671-675. https://doi.org/10.1038/nmeth.2089

641 Serra-Maluquer, X., Mencuccini, M., \& Martínez-Vilalta, J. (2018). Changes in tree resistance, 642 recovery and resilience across three successive extreme droughts in the Northeast Iberian 643 Peninsula. Oecologia 187: 343-354. https://doi.org/10.1007/s00442-018-4118-2

644 Vicente-Serrano, S.M., Beguería, S., \& López-Moreno, J.I. (2010). A multiscalar drought index 645 sensitive to global warming: the Standardized Precipitation Evapotranspiration Index. Journal of 646 Climate, 23; 1696-1718. https://doi.org/10.1175/2009JCLI2909.1

647 Vicente-Serrano, S.M., Tomas-Burguera, M., Beguería, S., Reig, F., Latorre, B., Peña-Gallardo, 648 M., ... González-Hidalgo, J.C. (2017). A high resolution dataset of drought indices for Spain. 649 Data, 2: 22. https://doi.org/10.3390/data2030022

650 Vilà-Cabrera, A., Martínez-Vilalta, J., \& Retana, J. (2015). Functional trait variation along 651 environmental gradients in temperate and Mediterranean trees. Global Ecology and 652 Biogeography, 24; 1377-1389. https://doi.org/10.1111/geb.12379 
653 Vilà-Cabrera, A., Premoli, A.C., \& Jump, A.S. (2019). Refining predictions of population decline 654 at species' rear edges. Global Change Biology, 25: 1549655 1560. https://doi.org/10.1111/gcb.14597

656 Vilà-Cabrera, A., \& Jump, A.J. (2019). Greater growth stability of trees in marginal habitats 657 suggests a patchy pattern of population loss and retention in response to increased drought at the 658 rear edge. Ecology Letters, 22: 1439-1448. https://doi.org/10.1111/ele.13329

659 Wright, I.J., Reich, P.B., Westoby, M., Ackerly, D.D., Baruch, Z., Bongers, F., ... Villar, R. 660 (2004). The worldwide leaf economics spectrum. Nature. 428; 821-827. 661 https://doi.org/10.1038/nature02403

662 Zang, C., Hartl-Meier, C., Dittmar, C., Rothe, A., \& Menzel, A. (2014). Patterns of drought 663 tolerance in major European temperate forest trees: climatic drivers and levels of variability. 664 Global Change Biology, 20; 3767-3779. https://doi.org/10.1111/gcb.12637

665

666 667 
669 Table 1. Description of the sampled sites. Coordinates, altitude, mean annual temperature (MAT), 670 mean maximum (MATmax) and minimum (MATmin) temperatures, and mean annual 671 precipitation (MAP) are given. Temperature and precipitation data were extracted from the 672 Climatic Atlas of the Iberian Peninsula (Ninyerola, Pons \& Roure 2005). Position in the sampled 673 climatic gradient is indicated by the site type variable as WET, INT (intermediate) and DRY. 674 Name of the sampled localities are given as sites. Tree data variables are presented as means \pm 675 SE (standard error).

676 Table 2. Results of the generalized linear models evaluating intraspecific effects of site, diameter at breast height (DBH), competition Index (CI), Specific leaf area (SLA) and wood density (WD) on accumulated growth decreases (AcGD) and accumulated growth enhancements (AcGE) caused by recurrent dry and wet years, respectively. One model per species is presented. For site, results of post-hoc analyses between the different sites are reported, + means that at least two sampled sites differ in values of AcGE or AcGD. For continuous variables, variable estimates are reported once effects are significant $(p<0.05)$. ns indicates non-significant effect. Significance levels: ${ }^{*}, \mathrm{p}<0.05 ; * *, \mathrm{p}<0.01, * * *, p<0.001 .+$ indicate differences among site levels.

Table 3. Mixed models of intraspecific (All) and intra-population (Dry, Int, Wet) effects of 685 accumulated growth decreases (AcGD) and enhancements (AcGE), year and year*AcGD/AcGE interaction on log-transformed basal area increment (BAI). Estimates are given for significant or marginally significant variables. Marginal $\left(\mathrm{R}^{2} \mathrm{~m}\right)$ and conditional $\mathrm{R}^{2}\left(\mathrm{R}^{2} \mathrm{c}\right)$ values for each model are also given. Significant levels: $+, p<0.1{ }^{*}, p<0.05 ;^{* *}, p<0.01{ }^{* * *}, p<0.001$. 
692

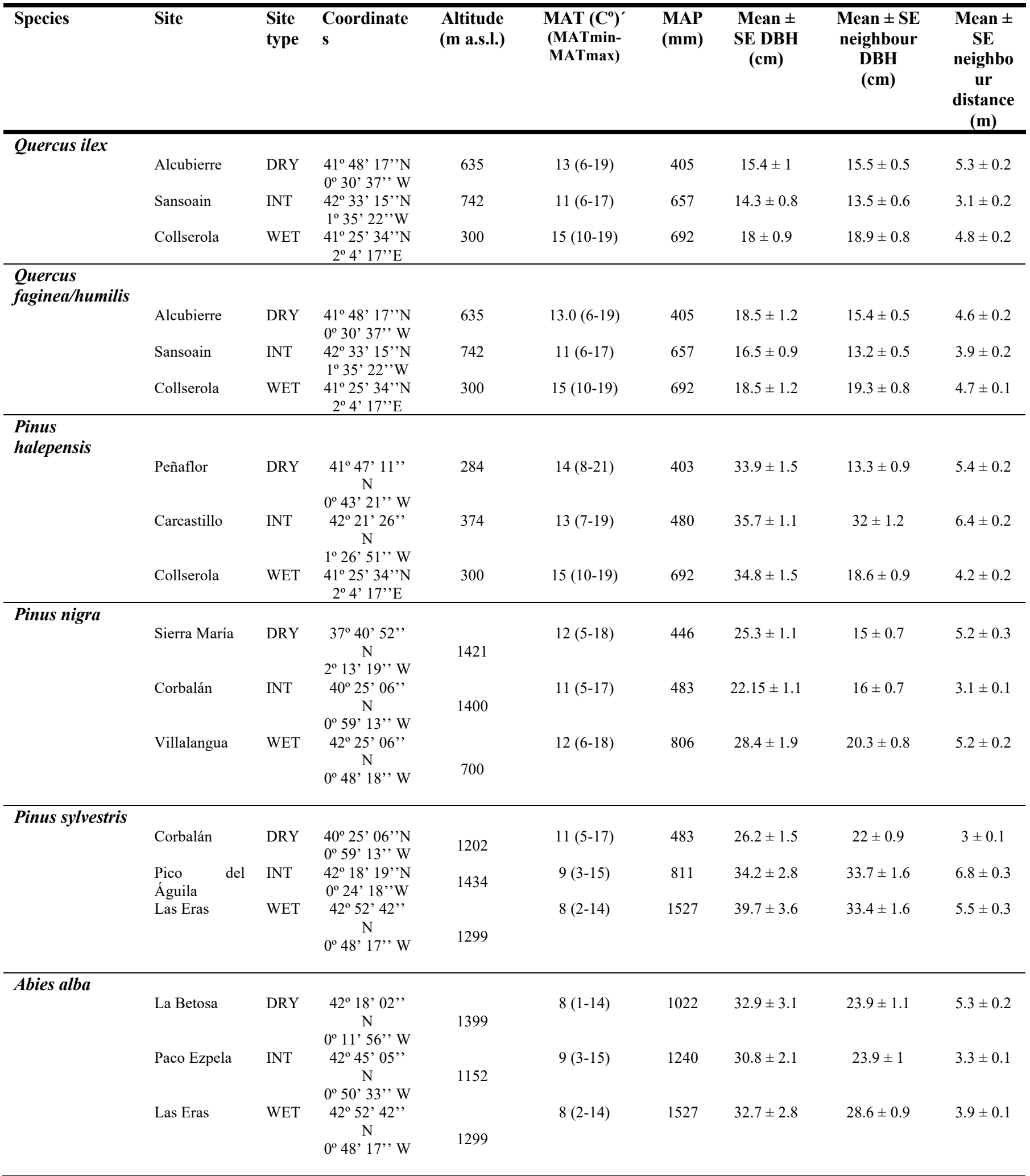

693 
Table 2.

\begin{tabular}{lcccccc}
\hline Species & Variable & Site & DBH & CI & SLA & WD \\
\hline Quercus ilex & AcGD & + & $\mathrm{ns}$ & $\mathrm{ns}$ & $\mathrm{ns}$ & $\mathrm{ns}$ \\
& $\mathrm{AcGE}$ & + & $\mathrm{ns}$ & $\mathrm{ns}$ & $\mathrm{ns}$ & $\mathrm{ns}$ \\
Quercus faginea/humilis & $\mathrm{AcGD}$ & + & $\mathrm{ns}$ & $\mathrm{ns}$ & $\mathrm{ns}$ & $\mathrm{ns}$ \\
& $\mathrm{AcGE}$ & + & $\mathrm{ns}$ & $\mathrm{ns}$ & $\mathrm{ns}$ & $\mathrm{ns}$ \\
Pinus halepensis & $\mathrm{AcGD}$ & + & $\mathrm{ns}$ & $\mathrm{ns}$ & $\mathrm{ns}$ & $\mathrm{ns}$ \\
& $\mathrm{AcGE}$ & + & $\mathrm{ns}$ & $\mathrm{ns}$ & $\mathrm{ns}$ & $\mathrm{ns}$ \\
Pinus nigra & $\mathrm{AcGD}$ & + & $0.27^{*}$ & $0.22^{* *}$ & $\mathrm{~ns}$ & $\mathrm{~ns}$ \\
& $\mathrm{AcGE}$ & $\mathrm{ns}$ & $\mathrm{ns}$ & $\mathrm{ns}$ & $\mathrm{ns}$ & $\mathrm{ns}$ \\
Pinus sylvestris & $\mathrm{AcGD}$ & + & $\mathrm{ns}$ & $\mathrm{ns}$ & $\mathrm{ns}$ & $\mathrm{ns}$ \\
& $\mathrm{AcGE}$ & + & $\mathrm{ns}$ & $\mathrm{ns}$ & $-1.56^{*}$ & $\mathrm{~ns}$ \\
Abies alba & $\mathrm{AcGD}$ & + & $\mathrm{ns}$ & $\mathrm{ns}$ & $1.52^{*}$ & $\mathrm{~ns}$ \\
& $\mathrm{AcGE}$ & + & $-0.56^{*}$ & $-0.46^{*}$ & $-2.57^{* * *}$ & $\mathrm{~ns}$ \\
\hline
\end{tabular}

696

697

698

699

700

701

702

703

704

705

706

707

708

709

710

711

712 
714

\begin{tabular}{|c|c|c|c|c|c|c|c|c|}
\hline Species & Site & Year & AcGD & AcGE & Year*AcGD & $\begin{array}{l}\text { Year * } \\
\text { AcGE }\end{array}$ & $\mathbf{R}^{2} \mathbf{m}$ & $\mathbf{R}^{2} \mathbf{c}$ \\
\hline \multirow[t]{4}{*}{ Quercus ilex } & All & $-0.010^{*}$ & & $-16.06 * * *$ & & $0.008 * * *$ & 0.03 & 0.41 \\
\hline & Dry & - & & & & & 0.009 & 0.48 \\
\hline & Int & & & $-18.833 * * *$ & & $0.009 * * *$ & 0.10 & 0.47 \\
\hline & Wet & & $7.655^{*}$ & $-14.003 * *$ & $-0.003 * *$ & $0.006 * *$ & 0.06 & 0.38 \\
\hline \multirow{4}{*}{ Quercus faginea/humilis } & All & $0.010^{* *}$ & $3.086^{*}$ & $-3.151^{*}$ & $-0.002 *$ & $0.002 *$ & 0.03 & 0.64 \\
\hline & Dry & & $9.839 *$ & $-8.364 *$ & $-0.005^{*}$ & $0.004 * *$ & 0.05 & 0.74 \\
\hline & Int & $-0.013+$ & & $-18.284^{* *}$ & - & $0.009 * *$ & 0.05 & 0.70 \\
\hline & Wet & - & & & & & 0.16 & 0.54 \\
\hline \multirow[t]{4}{*}{ Pinus halepensis } & All & $0.028 * * *$ & $17.500 * * *$ & $-9.050 * * *$ & $-0.009 * * *$ & $0.005 * * *$ & 0.09 & 0.52 \\
\hline & Dry & $-0.064 * * *$ & $11.397 * * *$ & $-35.537 * * *$ & $-0.006 * * *$ & $0.018 * * *$ & 0.25 & 0.59 \\
\hline & Int & & $14.060 * * *$ & $-16.830 * * *$ & $-0.007 * * *$ & $0.008 * * *$ & 0.04 & 0.48 \\
\hline & Wet & $0.026^{* *}$ & $12.179 * *$ & $-9.363^{*}$ & $-0.006^{* * *}$ & $0.005^{* *}$ & 0.02 & 0.58 \\
\hline \multirow[t]{4}{*}{ Pinus nigra } & All & $-0.040 * * *$ & $6.612 * * *$ & $-25.558 * * *$ & $-0.003 * * *$ & $0.013 * * *$ & 0.11 & 0.57 \\
\hline & Dry & $-0.039 * *$ & $16.635^{* * *}$ & $-36.768 * * *$ & $-0.008 * * *$ & $0.019 * * *$ & 0.38 & 0.65 \\
\hline & Int & & $5.046^{* *}$ & $-11.849^{*}$ & $-0.003 * *$ & $0.006^{*}$ & 0.07 & 0.47 \\
\hline & Wet & & $23.692 * * *$ & $-15.310 * * *$ & $-0.012 * * *$ & $0.008 * * *$ & 0.14 & 0.77 \\
\hline \multirow[t]{4}{*}{ Pinus sylvestris } & All & $-0.026^{* * *}$ & $5.274 * * *$ & $-21.040 * * *$ & $-0.003 * * *$ & $0.011 * * *$ & 0.08 & 0.60 \\
\hline & Dry & $-0.025^{*}$ & & & & & 0.12 & 0.54 \\
\hline & Int & & $14.633^{* * *}$ & $-15.337 * * *$ & $-0.007 * * *$ & $0.008 * * *$ & 0.03 & 0.66 \\
\hline & Wet & $-0.073 * * *$ & $16.226^{* * *}$ & $-70.961 * * *$ & $-0.008 * * *$ & $0.036 * * *$ & 0.41 & 0.81 \\
\hline \multirow[t]{4}{*}{ Abies alba } & All & & $21.045^{* * *}$ & $-33.614 * * *$ & $-0.011 * * *$ & $0.017 * * *$ & 0.12 & 0.79 \\
\hline & Dry & $0.009^{*}$ & $30.595 * * *$ & $-31.928 * * *$ & $-0.015^{* * *}$ & $0.016^{* * *}$ & 0.24 & 0.92 \\
\hline & Int & & $10.197+$ & $-34.479 * * *$ & $-0.005+$ & $0.017 * * *$ & 0.13 & 0.69 \\
\hline & Wet & $0.016^{*}$ & $31.043 * *$ & $-24.798 * * *$ & $-0.016^{* * *}$ & $0.012 * * *$ & 0.16 & 0.82 \\
\hline
\end{tabular}


Figure 1. Theoretical effects of consecutive dry and wet years on radial growth trends. Two successive dry and wet years (vertical red and blue rectangles, respectively) cause low and high growth (red and blue arrows respectively). The magnitude of these low and high growth years (AcGD, accumulated growth decreases; AcGE, and accumulated growth enhancements) could end up determining the overall tree performance within a specific period (i. e. different growth trends, represented by grey dashed lines).

Figure 2. Growth trajectories represented as linear regressions of log-transformed Standardized Basal Area Increment (BAI) against calendar year (from 1990 to 2016) for each studied tree population. Boxplots of accumulated growth decreases (AcGD) and accumulated growth enhancements (AcGE) are shown for each population. Colour defines population classification being red, dry populations (DRY), green, intermediate populations (INT), and blue, wet populations (WET). In the boxplots, different letters indicate significant $(p<0.05)$ differences in AcGD or AcGE between populations following post hoc tests of the generalized linear models (Table 2.)

733

Figure 3. Changes in growth trends during 1990-2016 period depending on (a) accumulated growth decrease (AcGD) and (b) accumulated growth enhancement (AcGE) at intraspecific level. Individual trees irrespective of their population are classified in three categories depending on the intensity of AcGD or AcGE: L, low AcGD and AcGE $=1-32 \%$, I, intermediate AcGD and AcGE $=33-65 \%$; , high AcGD and AcGE $=66-100 \%$. Significance levels $(p)$ from the interaction term of Year * AcGD/AcGE in the intraspecific models are given (Table 3). ns $=$ nonsignificant.

741

Figure 4. Changes in growth trends during 1990-2016 period depending on (a) accumulated growth decrease (AcGD) (b) accumulated growth enhancement (AcGE) at intra-population level. Individual trees within populations are classified in three categories depending on the intensity of

745 AcGD or AcGE: L, low AcGD and AcGE $=1-32 \%$, I, intermediate AcGD and AcGE $=33-$ 
747 Year * AcGD/AcGE in the intra-population models are given (Table 3). ns = non-significant.

748 Colour defines population classification being red, dry populations (DRY), green, intermediate

749 populations (INT), and blue, wet populations (WET).

750

751

752

753

754

755

756

757

758

759

760

761

762

763

764

765

766

767

768

769

770

771

772

773

774

775 
Figure 1

781

782

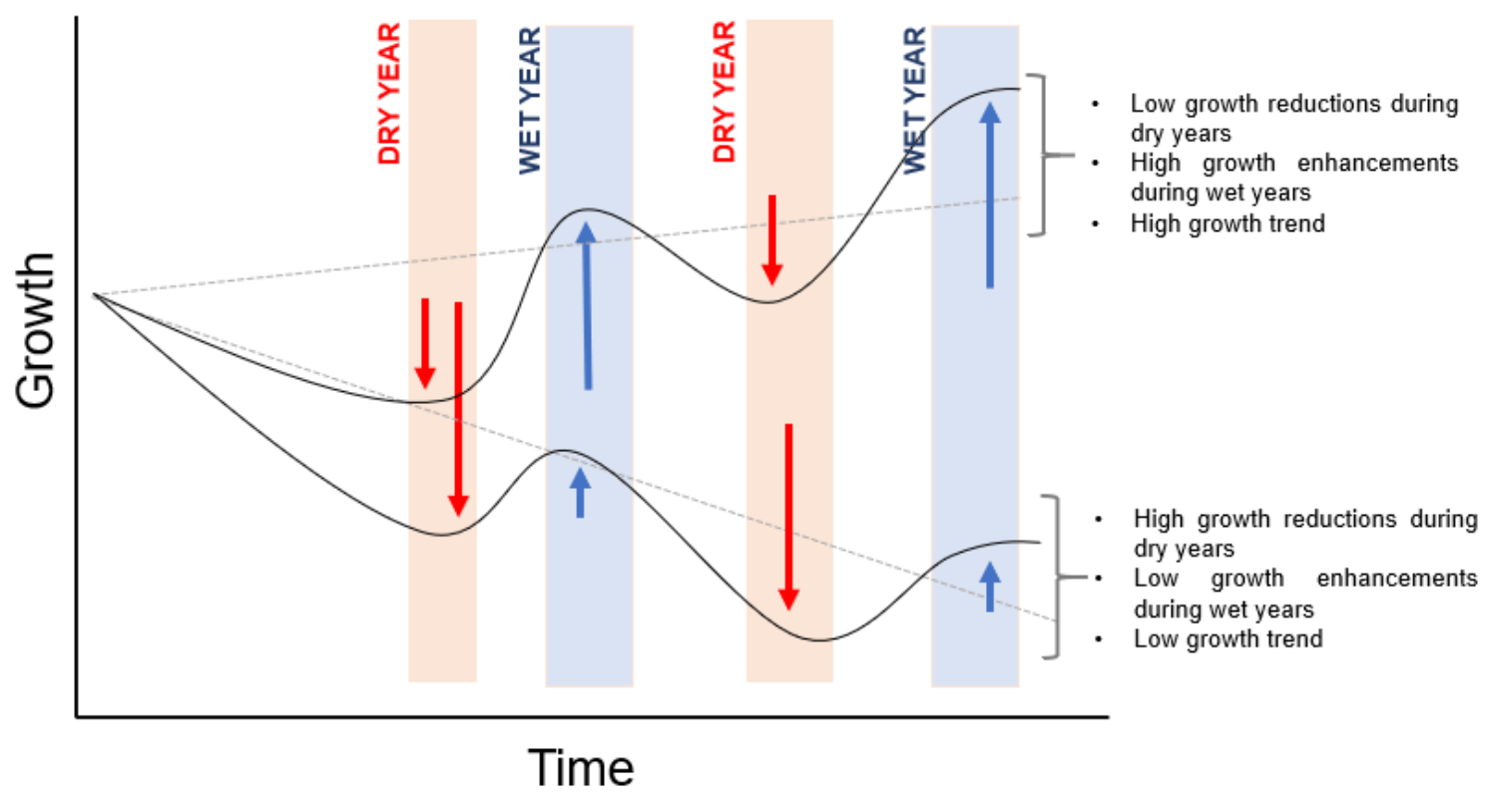

783

784

785 
Figure 2
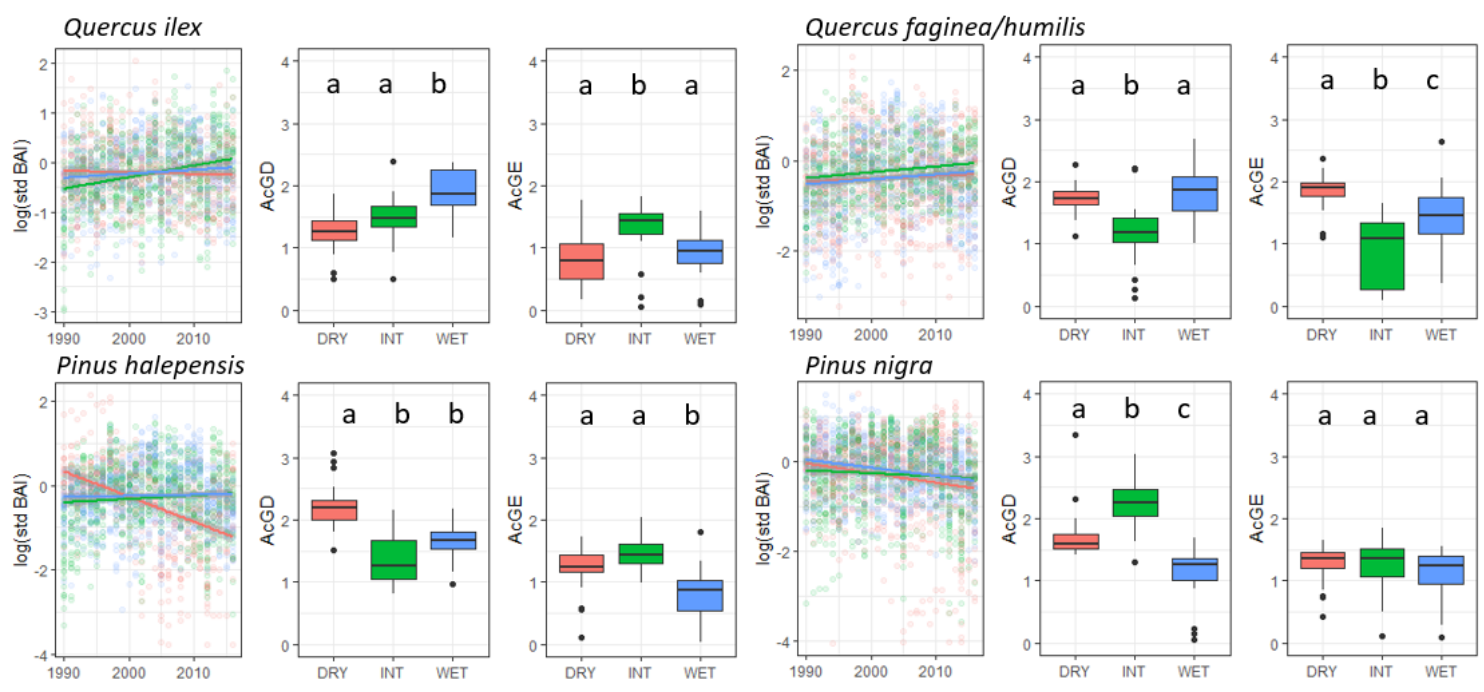

787
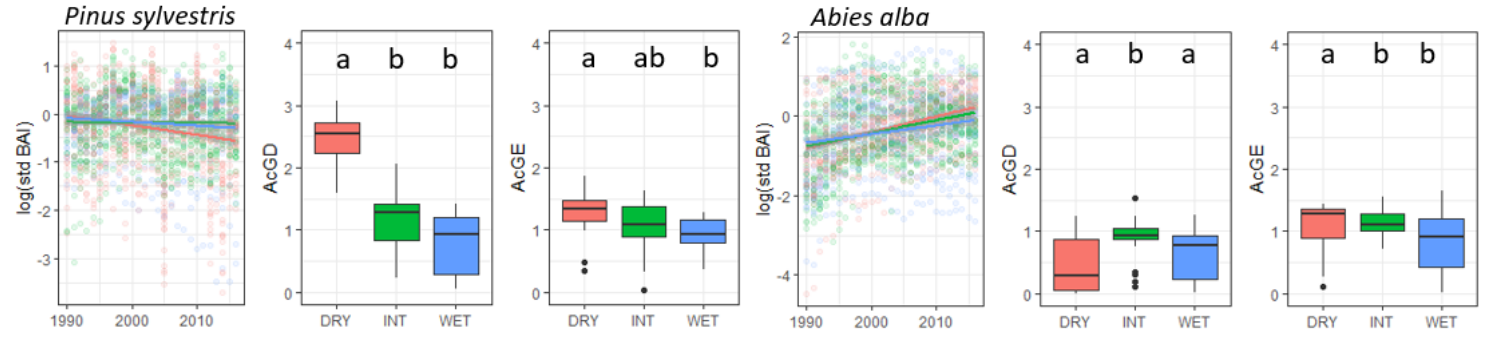

788

789 


\section{Quercus} ilex

Quercus
faginea /
Quercus humilis

Pinus halepensis

Pinus

nigra

Quercus humilis

(a) Accumulated growth decreases (AcGD)

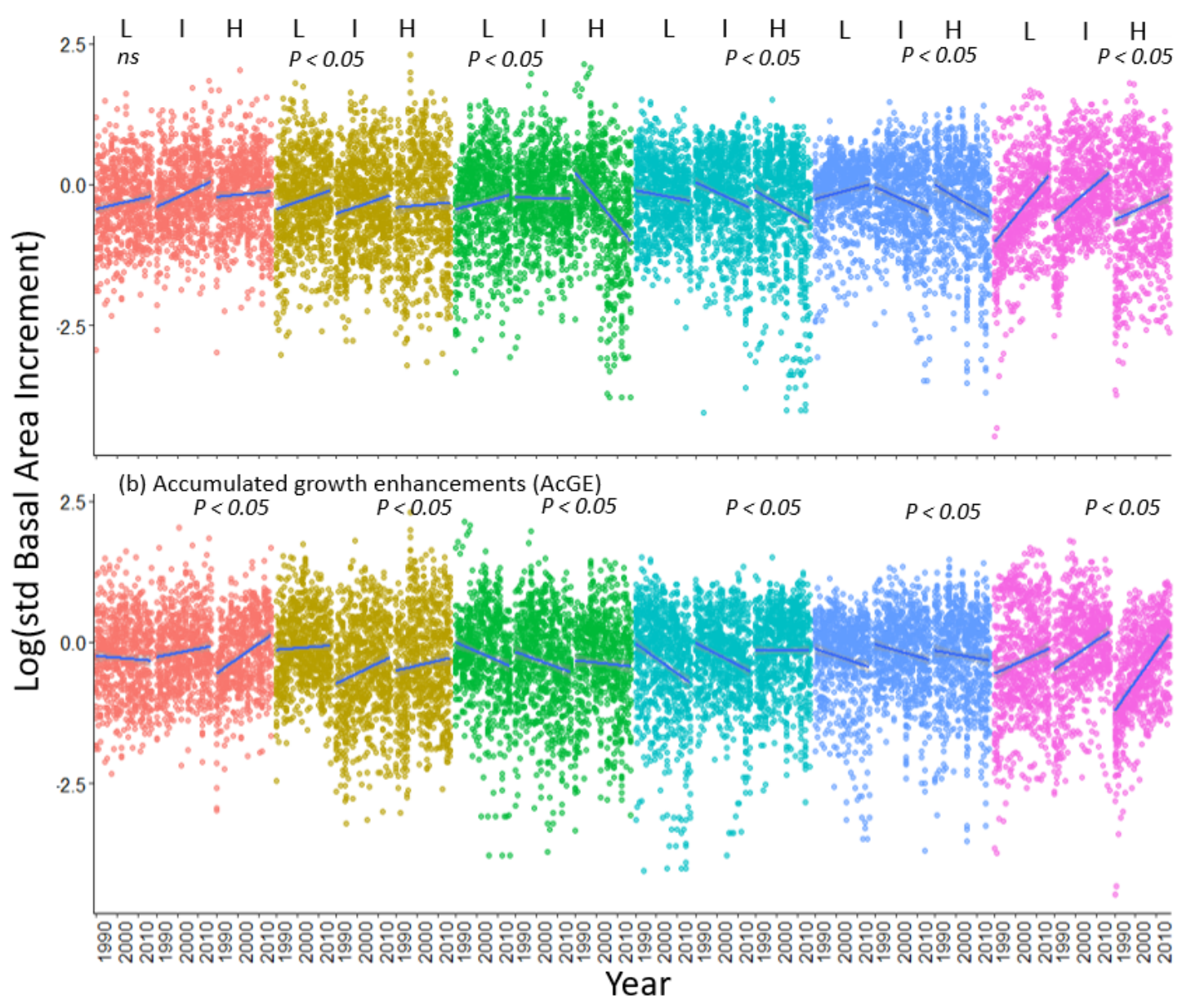


(a) ACCUMULATED GROWTH DECREASES (ACGD) Quercus ilex

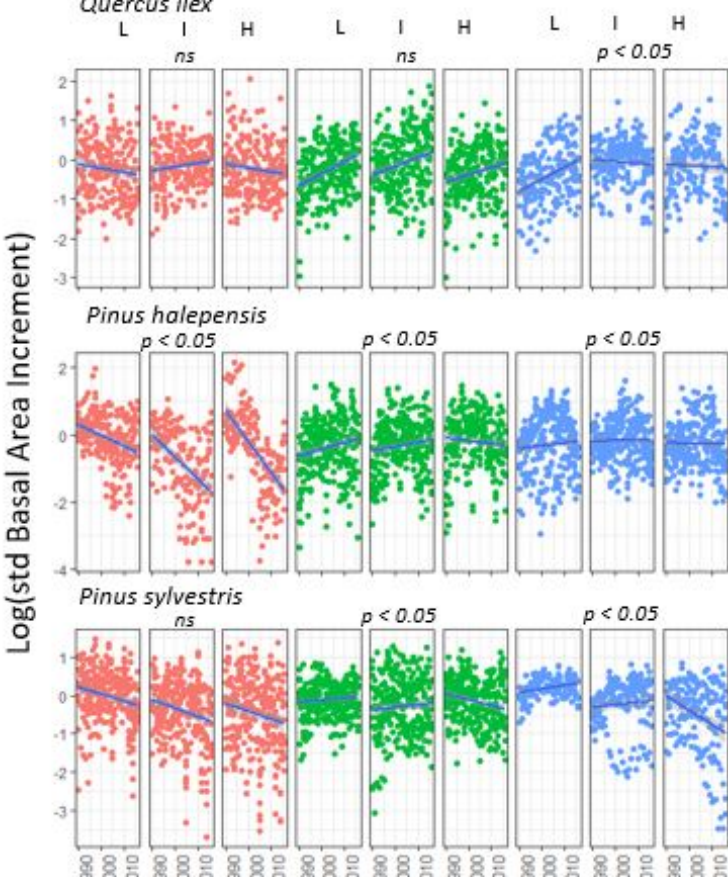

880 Year

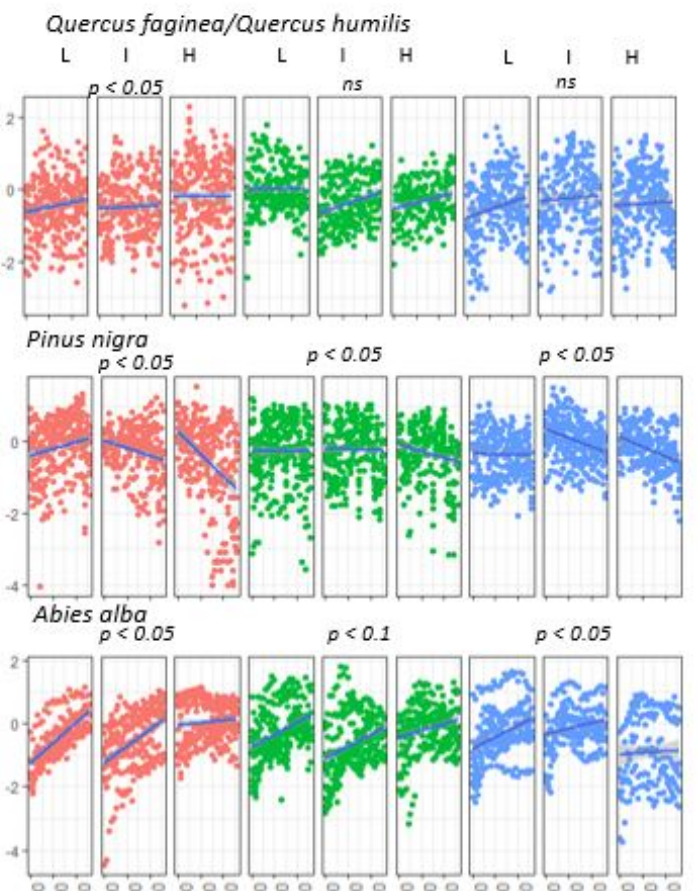

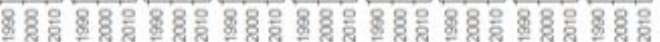

(b) ACCUMULATED GROWTH ENHANCEMENTS (ACGE)

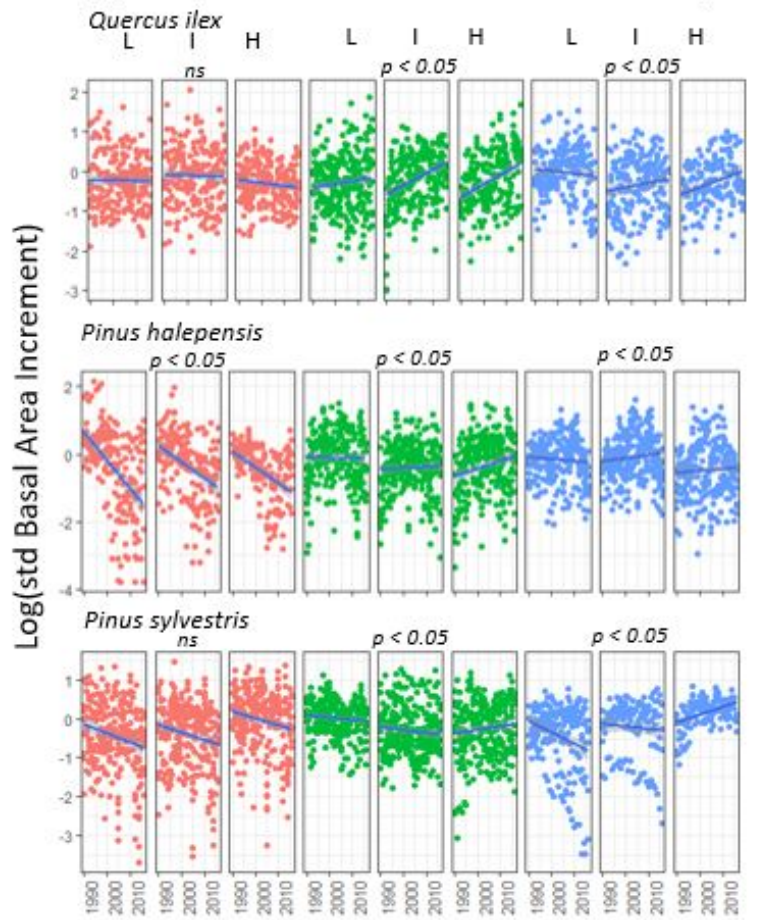

Quercus faginea/Quercus humilis $\mathrm{H}_{\mathrm{H}} \mathrm{L}_{\mathrm{L}} \quad \mathrm{H}$

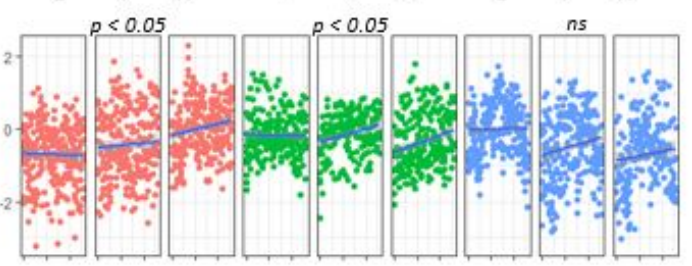

Pinus nigra
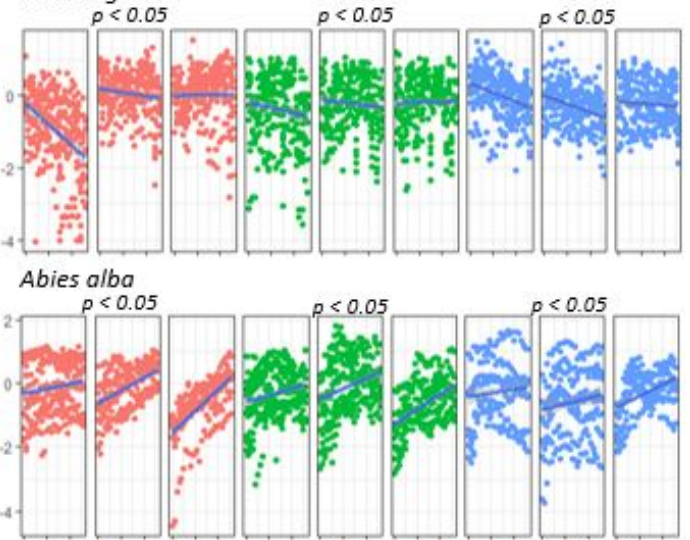

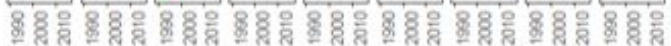
Year 